\title{
A DOCUMENTAÇÃO E A DIVULGAÇÃO DO SABER LINGUÍSTICO NA REVISTA DO IHGB
}

\author{
Dantielli Assumpção Garcia** \\ José Horta Nunes***
}

Resumo: Neste trabalho, da perspectiva teórica da Análise de Discurso em articulação com a História das Ideias Linguísticas, discorreremos sobre a prática de documentação e divulgação do saber linguístico realizada pela Revista do Instituto Histórico e Geográfico Brasileiro. Para isso, analisaremos inicialmente as Revistas do IHGB do século XIX (1839-1889), mostrando como o saber linguístico se constitui no discurso do IHGB e, em seguida, a Revista do IHGB n. 400 (1998), indice que organiza e divulga toda a produção da RIHGB desde 1839 até 1998. Mobilizamos como noções teóricas: arquivo, documentação linguística e divulgação científica. Pretendemos, com este trabalho, mostrar como a documentação e a divulgação estabilizam alguns sentidos e apagam outros para o saber linguístico brasileiro.

Palavras-chave: Documentação linguística. Divulgação científica. Revista do IHGB.

\section{INTRODUÇÃO}

Em 1838, funda-se na cidade do Rio de Janeiro, com base em um projeto apresentado à Sociedade Auxiliadora da Indústria Nacional (SAIN) por Januário da Cunha Barbosa e por Raymundo José da Cunha Mattos, o Instituto Histórico e Geográfico Brasileiro (IHGB). Essa instituição se constitui com o objetivo de "coligir, metodizar, publicar ou arquivar documentos" (Extracto dos Estatutos, RIHGB n. 1, 1839, p. 18) relativos à história e à geografia do Brasil. Esses materiais servirão para que seja composta, pelos escritores da sociedade brasileira e internacional, uma história do Brasil. Um lugar em que se pode observar a organização e divulgação desses textos sobre a história e a geografia do Brasil é a Revista do Instituto Histórico e Geográfico Brasileiro (RIHGB). A RIHGB teve sua primeira publicação em 1839 e mantém sua produção

\footnotetext{
* Trabalho resultado da tese de doutorado (A Revista do IHGB: um gesto de documentação linguística, FAPESP, proc. $\mathrm{n}^{\circ}$ 07/58250-1), desenvolvida no Programa de Pós-Graduação em Estudos Linguísticos da UNESP, de São José do Rio Preto, sob a orientação do Prof. Dr. José Horta Nunes.

** Doutora em Estudos Linguísticos, PG-UNESP. Email: dantielligarcia@gmail.com

*** Docente doutor do Departamento de Estudos Linguísticos e Literários da UNESP. Email: horta@ibilce.unesp.br
} 
até os dias de hoje. Nela, podemos notar a descrição das atividades da Instituição, os materiais sobre a história e a geografia do Brasil coletados, arquivados e divulgados na revista. Em meio a esses materiais, encontramos os que dizem respeito ao saber linguístico.

Em nosso trabalho, da perspectiva teórica da Análise de Discurso em articulação com a História das Ideias Linguísticas, objetivamos analisar como se constrói e se divulga um saber linguístico na Revista. Pretendemos perceber que formas de saberes linguísticos são coletadas/metodizadas/divulgadas na RIHGB. Nosso material de análise são as RIHGB de 1839 até 1889 (Brasil Império). Analisaremos também a RIHGB n. 400 (1998), que se constitui como um índice das publicações da RIHGB.

Nosso trabalho se divide em: (i) O Instituto Histórico e Geográfico Brasileiro e sua revista - em que refletiremos sobre a fundação do IHGB no Brasil do século XIX e o surgimento de sua revista -; (ii) A documentação e a divulgação na RIHGB - nessa parte, discorreremos sobre os conceitos teóricos mobilizados para a compreensão da RIHGB -; (iii) O saber linguístico nas RIHGB do século XIX - em que analisaremos como o saber linguístico aparece na RIHGB durante o século XIX -; e (iv) $A$ RIHGB n. 400: uma prática de leitura, interpretação e divulgação - em que mostraremos como o saber linguístico produzido pelo IHGB é sistematizado na RIHGB n. 400, que surge com o objetivo de divulgar a produção do Instituto.

\section{O INSTITUTO HISTÓRICO E GEOGRÁFICO BRASILEIRO E SUA REVISTA}

Para analisarmos a fundação do Instituto Histórico e Geográfico Brasileiro, baseamo-nos nos seguintes trabalhos: Faria (1965), Guimarães (1988), Schwarcz (1989, 1993), Guimarães e Holten (1997), Guimarães (1995). Esses trabalhos foram escolhidos em virtude de sua grande representatividade nos estudos sobre o IHGB e sua Revista. 
Falar do Instituto Histórico e Geográfico Brasileiro é discorrer de algum modo sobre a organização, a sistematização e a divulgação de um saber sobre o Brasil. Essa instituição foi fundada em 1838 com a finalidade de "colligir e methodisar os documentos historicos e geographicos interessantes á história do Brazil” (RIHGB, tomo 1, 1839, p. 6). A meta do IHGB era documentar/arquivar materiais referentes ao Brasil. Nas revistas, podemos perceber que são estabelecidos direcionamentos para essa prática de documentação. Nesse gesto de documentação, a Revista do IHGB formula-se com o objetivo de construir e divulgar um arquivo que possa ser "aproveitado" pelos escritores da história e da geografia do Brasil.

Foram o militar Raimundo José da Cunha Mattos e o cônego Januário da Cunha Barbosa que desenvolveram um projeto de um instituto histórico. Eles eram membros também do Instituto Histórico de Paris. Guimarães (1988, p. 13) aponta que a tradição do IHGB pode ser vinculada "não só em termos de sua concepção historiográfica, como também em termos da forma específica de sociabilidade" às sociedades estamentais, mais precisamente, ao Institut Historique de Paris (IHP). Nos diz o autor (1988, p. 13): "Os contatos entre as duas instituições estendiam-se ainda à troca de publicações e correspondência, e à abertura de espaço na revista do instituto parisiense para o tratamento de temas e veiculação de notícias relativas ao Brasil". Ainda nos dizeres de Guimarães (1988, p. 14): "podemos pensar o Institut Historique de Paris como fornecedor dos parâmetros de trabalho historiográfico ao IHGB, e instância legitimadora, cuja chancela poderia dar um peso relevante e destaque a uma história nacional em construção, como a brasileira". Ressalta Guimarães (2002, p. 192) que o projeto do IHP era constituir uma história de caráter universalista e por isso a instituição deveria construir uma rede internacional com sociedades congêneres de "forma a viabilizar esta escrita de uma história com pretensões verdadeiramente universais".

Como parte desse projeto, pode-se compreender o interesse do IHP em manter relações com o IHGB "a partir de sua fundação, que passava assim a integrar uma vasta rede de associações culturais e de membros correspondentes espalhados pelo mundo" (GUIMARÃES, 2002, p. 192). Embora o IHP tenha sido fornecedor dos parâmetros de trabalho historiográfico do IHGB, podemos notar que as concepções de 
história diferem entre as duas instituições. Enquanto o IHP pretendia constituir uma história universalista, o IHGB pretendia coletar materiais que servissem para a construção de uma história nacional, que descrevesse o Brasil enquanto uma unidade nacional, mas que também discorresse sobre a autonomia de suas províncias. As relações com as outras instituições, no IHGB, são estabelecidas com o objetivo de conseguir documentos sobre o Brasil que estão arquivados nessas instituições. O interesse do IHGB é "resgatar" documentos interessantes ao IHGB e à história e geografia do Brasil.

Faria (1965, p. 119) expõe que o Instituto Histórico e Geográfico Brasileiro sempre recebeu as "mais vivas manifestações de interesse e simpatia" do IHP. O IHGB era visto como uma espécie de "irmã mais nova" do IHP, como uma instituição que deveria ser lembrada nos discursos do Instituto Histórico de Paris,

Seja porque os brasileiros, por seu lado, se empenharam em filiarse fielmente ao Instituto Histórico de Paris, enviando-lhe estatutos, diplomas, notícias, etc., seja porque realmente as relações entre colegas franceses e brasileiros era das mais amistosas, incluindo mesmo casos de velhas amizades pessoais, nenhum outro Instituto estrangeiro recebeu tantas atenções como o nosso (FARIA, 1965, p. 119).

Aqui, podemos notar como as relações entre as instituições se dão. São salientados tanto os aspectos acadêmicos como os aspectos pessoais. Para fazer parte das instituições que detêm o poder de "escrever" uma história, o sujeito tem que ser ao mesmo tempo intelectual e manter relações sociais, pessoais com os outros sujeitos com os quais convive, seja nas sociedades internacionais, seja no IHGB.

Guimarães e Holten (1997, p. 3) mostram que o IHGB surgiu em momentos de crise institucional, em situações de redefinição nacional. "No Brasil, havia a necessidade de construir uma memória nacional, que minimizasse um legado colonial desagregador e fosse capaz de contribuir para a união das províncias do Império". Ainda, conforme as autoras (1997, p. 3): 
O império brasileiro, independente de Portugal desde 1822, dava os seus primeiros passos, atravessando uma conjuntura adversa, governado por regentes, desde a abdicação do Pedro I em 1831. Neste contexto, a fundação do Instituto deve ser entendida como um acontecimento político e cultural da maior relevância, capaz de contribuir tanto para a preservação da unidade nacional, quanto para o fortalecimento do regime.

Guimarães (1995) aponta que a meta do IHGB era dotar o país, recém-independente, de "um passado adequado às pretensões da monarquia instaurada". Havia a exclusão deliberada, nos textos do IHGB, de insurreições, traumas e conflitos. Quando esses fatos históricos eram documentados, eles "eram atribuídos à mocidade do País, aos arroubos da juventude” (p. 602). Ainda nas palavras da autora (p. 602):

Atravessados os anos rebeldes da adolescência, o Estado brasileiro, segundo os registros dos integrantes do Instituto, teria chegado à idade adulta numa condição privilegiada. A paz fora garantida e a unidade das províncias preservada. A turbulência política e a fragmentação das repúblicas vizinhas, sucessoras das antigas colônias espanholas, passaram ao largo da Terra de Santa Cruz. O "Príncipe Perfeito", pupilo predileto dos fundadores da "Casa", cumpria o seu papel de monarca conciliador e amante das letras.

Argumenta Schwarcz (1993, p. 135) que, com a fundação do IHGB, busca-se centralizar o poder e todas as discussões em torno de uma história sobre uma nação em formação:

Com relação ao IHGB, toda a produção intelectual esteve profundamente associada ao Estado Imperial, entendido como "a causa última da unidade política do paiz contra o espírito maligno da anarquia" (RIHGB, 1840, p. 505). Nascido em meio a uma conjuntura em que se luta pela preservação da soberania do país o IHGB identificou-se com a política centralizadora daquele 
período, mantendo desde a origem a finalidade explícita de construir uma "memória nacional" em que a produção intelectual e relações de poder estivessem tão irmanadas que não haveria lugar para discórdia. "Guardiões do Imperador", os sócios do IHGB souberam garantir seu espaço no interior da nova organização política justificando a manutenção da unidade interna, causa última de um Estado "que nasceu Império" e debatia-se ante a possibilidade da dissensão.

Um modo, como já ressaltamos, de produzir/divulgar uma historiografia elaborada pela(os) elite/membros do IHGB foi a Revista do IHGB. A Revista, no século XIX, tinha um público certo: os sócios do Instituto e as sociedades nacionais e internacionais com as quais o IHGB mantinha contato. A RIHGB, conforme Guimarães (1988, p. 21), constitui um "foro privilegiado" para notar o projeto historiográfico brasileiro:

Além de registrar as atividades da instituição através de seus relatórios, divulgar cerimônias e atos comemorativos diversos, as páginas da Revista se abrem à publicação de fontes primárias como forma de preservar a informação nelas contidas - aliás, parte substancial de seu conteúdo nos primeiros tempos - de artigos, biografias e resenhas de obras (GUIMARÃES, 1988, p. 21).

Dessa forma, ao se fortalecer como Instituição, o IHGB também produz o fortalecimento do Brasil. O IHGB dará unidade ao Brasil, centralizará o debate sobre as questões históricas, geográficas e também linguísticas. A revista da instituição será o lugar em que esse dizer sobre o Brasil será documentado e divulgado. 


\section{A DOCUMENTAÇÃO E A DIVULGAÇÃO NA REVISTA DO IHGB}

Nesta parte de nosso trabalho, apresentaremos as noções teóricas mobilizadas para a compreensão da RIHGB. Os conceitos operacionalizados são: arquivo, documentação linguistica e divulgação científica.

A discussão sobre as novas formas de leitura de arquivo na Análise de Discurso foi impulsionada por um texto em que Michel Pêcheux (1993) refletia sobre as mudanças tecnológicas ligadas à leitura em ciências humanas. Segundo o autor (1993, p. 57), o arquivo é entendido, em sentido amplo, como "campo de documentos pertinentes e disponíveis sobre uma questão". Ao analisar as revistas do IHGB, pode-se notar como se constitui um arquivo sobre as questões linguísticas, sobre as línguas do território brasileiro.

Pêcheux (1993) explicita que há duas tradições de trabalho de arquivo: (i) literária e (ii) científica. Salienta que tradicionalmente os literatos são os profissionais de leitura de arquivo e os cientistas são os fabricantes das novas tecnologias e sustentadores das leituras dos literatos. Para o autor, essa separação entre o literário e o científico revela uma divisão social do trabalho de leitura: "a alguns, o direito de produzir leituras originais, logo 'interpretações' [...]; a outros, a tarefa subalterna de preparar e de sustentar [...] as ditas 'interpretações"' (1993, p. 58). Nas RIHGB, temos uma divisão no trabalho de arquivo: a alguns é dada a possibilidade de se produzir "interpretações" dos textos, a outros somente é permitido a coleta dos materiais sem um gesto de interpretação. Há uma relação tensa entre uma leitura "científica" e uma "literária". É a partir dessa diferença entre leituras que sustentamos que temos autores do IHGB e coletadores do IHGB. Aos autores, a compreensão da história e da geografia do Brasil; aos coletadores, a coleta/documentação da história e da geografia com os direcionamentos já dados pela RIHGB.

Orlandi (2006), ao falar sobre o arquivo, distingue dois tipos de memória: a memória discursiva e a memória institucionalizada. A memória discursiva é constituída pelo esquecimento, são todas as enunciações já ditas e silenciadas pelas condições de produção. Já a memória institucionalizada é o arquivo, estabilização dos sentidos. No 
arquivo, o dizer é documento, atestação dos sentidos, efeito de relações de forças; nele há um fechamento. Nas palavras da autora (2006, p. 22), a memória de arquivo "representa o discurso documental, a memória institucionalizada [...] é aquela justamente que fica disponível, arquivada em nossas instituições e da qual não esquecemos. A ela temos acesso, basta para isso consultar os arquivos onde ela está representada". Buscaremos aqui analisar que memória o IHGB constituiu em seus textos sobre as línguas do Brasil, ou seja, mostraremos que, ao documentar/arquivar dizeres sobre as línguas, algumas questões são apagadas e outros sentidos surgem como sendo únicos no imaginário do século XIX.

Nunes (2008, p. 91) salienta dois tipos de percursos ao se trabalhar com o arquivo: (i) percurso temático de arquivo e (ii) percurso temático no arquivo. $\mathrm{O}$ percurso temático no arquivo é aquele que se realiza em um ou mais arquivos para a composição de um corpus de análise. Dessa maneira realizam seus trabalhos Guilhaumou e Maldidier (1993). Entendem Guilhaumou e Maldidier (1993, p. 165-166) por tema uma noção que não remete nem à análise temática, tal como é praticada pelos críticos literários, nem aos empregos que dela se faz na linguística. “Essa noção supõe a distinção entre 'o horizonte de expectativas' - o conjunto de possibilidades atestadas em uma situação histórica dada - e o acontecimento discursivo ${ }^{1}$ que realiza uma dessas possibilidades, inscrito o tema em posição referencial." (GUILHAUMOU e MALDIDIER, 1993, p. 165-166). Conforme os autores (1993, p. 166, 167), a análise do trajeto temático

não se restringe aos limites da escrita, de um gênero, de uma série: ela reconstrói os caminhos daquilo que produz o acontecimento na linguagem.

\footnotetext{
${ }^{1}$ Conforme Guilhaumou e Maldidier (1993, p. 166), o acontecimento discursivo "não se confunde nem com a notícia, nem com o fato designado pelo poder, nem mesmo com o acontecimento construído pelo historiador. Ele é apreendido na consistência de enunciados que se entrecruzam em um momento dado". Para Pêcheux (1990, p. 19), o acontecimento é o fato novo, as primeiras declarações em "seu contexto de atualidade e no espaço de memória que ele convoca e que já começa a reorganizar". Segundo Zoppi-Fontana (1997, p. 51), o acontecimento é o "ponto de encontro entre uma atualidade e uma memória a partir da qual se reorganizam as práticas discursivas".
} 
$[\ldots]$

a análise do trajeto temático fundamenta-se em um vai-e-vem de atos linguageiros de uma grande diversidade e atos de linguagem que podemos analisar linguisticamente e nos quais os sujeitos podem ser especificados.

Já o percurso temático do arquivo é aquele construído em um arquivo, frequentemente ligado a uma instituição:

O que se estuda nesse caso não é exatamente como um tema está no arquivo ou atravessa vários arquivos, mas sim como o arquivo se constitui por temas, como ele ordena, classifica e constrói por meio de práticas documentais um discurso da história. Busca-se explicitar, de fato, as bases linguístico-discursivas do funcionamento do arquivo em relação a ele mesmo (NUNES, 2008, p. 91).

$\mathrm{Na}$ análise especificamente da Revista n. 400, explicitaremos o funcionamento do arquivo em relação a ele mesmo, ou seja, salientaremos como o gesto de sistematizar os saberes linguísticos, categorizar em um tema produz determinados sentidos e apaga outros.

Conforme Nunes (2008, p.82), o discurso documental pode ser visto enquanto uma prática de arquivo, mediada pelas instituições e que produz uma memória institucionalizada, estabilizadora de sentidos. Ao participar da construção do arquivo, o discurso documental estabelece uma regionalização da memória da ciência. Nas palavras do autor, o discurso documental é:

um saber científico que toma forma na relação com as instituições, os sujeitos da ciência, os meios de circulação do saber, dentre outros aspectos conjunturais. Esse discurso tem por materialidade específica os textos documentais, ou seja, textos que tomam esses materiais como objetos. Desse modo, trata-se de um discurso científico que se realiza por meio de textos documentais e que produz uma historicização da ciência (NUNES, 2008, p. 82-83). 
Nas RIHGB, além de uma prática de documentação, também podemos perceber uma prática de divulgação científica. Conforme Authier-Revuz (1998, p. 108), o objetivo do discurso de divulgação científica não é estender a comunidade de origem, mas sim disseminar, em direção ao exterior, conhecimentos científicos produzidos no interior de uma comunidade mais restrita. Na RIHGB n. 400, como veremos, temos disseminados trabalhos produzidos e coletados pelo IHGB para um público mais amplo e não somente para a sociedade da instituição. Ainda segundo a autora (1998, p. 108), o discurso de divulgação científica seria uma prática de reformulação de um discurso fonte em um discurso segundo que compreende tradução, resumo, resenha, textos pedagógicos a tal ou tal grupo social. Assim, o discurso de divulgação científica não corresponde ao discurso fonte, mas ele o mostra por meio de diversas formas. No caso específico do IHGB, na forma de um índice. Neste trabalho, portanto, nosso objetivo é perceber como a documentação de um saber linguístico produzido nas RIHGB é interpretado para ser divulgado na RIHGB n. 400.

\section{O SABER LINGUÍSTICO NAS RIHGB DO SÉCULO XIX}

Nesta parte, explicitaremos os materiais relativos ao saber linguístico produzido na $\mathrm{RIHGB}^{2}$. Para delimitarmos o modo como o saber linguístico aparece nos discursos da RIHGB, inicialmente efetuamos uma leitura/análise de todas as Revistas do IHGB de 1839 a 1889 (em nossa periodização, 52 tomos). A metodologia empreendida em nossa análise foi uma leitura de arquivo, isto é, realizamos uma leitura de toda a produção da Revista do IHGB concernente ao período imperial brasileiro. É importante ressaltar que, inicialmente, nossa leitura foi in loco (no próprio IHGB). Não foi uma leitura informatizada, pois no início de nossa pesquisa o IHGB ainda não dispunha de uma versão digitalizada de suas revistas ${ }^{3}$. Após esse contato com a revista, adquirimos nosso material de análise. Como etapa seguinte, iniciamos a

\footnotetext{
${ }^{2}$ Consideramos saber linguístico o saber produzido acerca das línguas do Brasil. Para isso, levamos em consideração as obras, os autores, as teorias, os conceitos que são mobilizados para a produção desse saber.

${ }^{3}$ Atualmente essa versão digital pode ser consultada no site: <http://www.ihgb.org.br/rihgb.php $>$.
} 
compreensão das RIHGB. Com base na compreensão das revistas, pudemos estabelecer domínios do corpus, em que notamos como o saber linguístico vai participando da formulação dos textos publicados na RIHGB. Os domínios, estabelecidos a partir do gesto de interpretação das revistas, foram:

- Domínio da Letra

- Domínio da Palavra (Histórico/Etimológico)

- Domínio do Comentário Linguístico

- Domínio dos Instrumentos Linguísticos

Para análise e categorização dos textos documentados na RIHGB, estamos considerando os títulos, os objetos ${ }^{4}$ (descritos) e os objetivos dos textos. Assim, os textos no Domínio da Letra refletem sobre a distinção entre letra e som e buscam estabelecer uma representação ortográfica para os sons das línguas. No Dominio da Palavra, trabalha-se a noção de palavra, além de delimitar a significação dos itens lexicais. Traz-se também a etimologia, objetivando indicar a origem das palavras bem como uma história do item lexical, filiando-se a um estudo documental da palavra. O Dominio do Comentário Linguístico é um pouco diferente dos demais; ele se constitui no interior de textos sobre a história, a geografia e a etnografia do Brasil. Nesses textos é trazido, às vezes, algum comentário sobre as línguas do Brasil. Esses comentários versam sobre aspectos fonéticos, etimológicos e até mesmo sobre a significação das palavras. Em alguns momentos, também se nomeiam coisas e seres. Nesses textos, temos a construção de um saber enciclopédico. Por fim, no Dominio dos Instrumentos Linguísticos, apresentam-se os instrumentos linguísticos produzidos ou coletados pela RIHGB.

Todos os textos selecionados tocam em algum desses domínios do saber linguístico. As teorias que estão permeando esses estudos publicados nas RIHGB são a Gramática Comparada, a Gramática Histórica e a Filologia. É necessário ressaltar que explicitamos esses textos divididos nos domínios para mostrar como, na RIHGB n. 400, um outro recorte

${ }^{4}$ Estamos entendendo objeto descrito como as obras documentadas/produzidas na RIHGB.

GARCIA; NUNES - A documentação e a divulgação... 
da produção das RIHGB foi feito ${ }^{5}$. Na RIHGB, diversos textos, considerados por nós como relativos a um saber linguístico brasileiro, são deixados de lado na tematização que propõe a RIHGB n. 400. Passemos aos textos, organizados nos domínios:

\section{Domínio da Letra}

- A Língua Geral do Amazonas e o Guarany - Observações sobre o alfabeto indígena, João Barbosa Rodrigues, 1888.

\section{Domínio da Palavra}

- Discurso sobre a palavra Brazil, José Silvestre Rebello, 1839.

- Discurso sobre a palavra Brazil, José Silvestre Rebello, 1840.

- Collecção de Etimologias Brasílicas, Francisco dos Prazeres Maranhão, 1846.

- Questões Americanas, Joaquim Caetano da Silva, 1863, 1866.

- O nome da América será americano? Candido Mendes de Almeida, 1876.

- Notas para a história da Patria. Quarto Artigo. Porque razão os indígenas de nosso litoral chamavam aos franceses de mair, e aos portugueses peró? Candido Mendes de Almeida, 1878.

- Tradição sobre a palavra Brazil, Ricardo Gumbleyton Daunt, 1884.

\footnotetext{
${ }^{5}$ É necessário ressaltar que na RIHGB aparecem textos do século XX. Esse século não foi analisado em nosso trabalho, que buscou refletir sobre o saber linguístico no Brasil Imperial.
} 


\section{Domínio do Comentário Linguístico}

- História dos índios cavalleiros, ou da nação Guaycurú, Francisco Rodrigues do Prado, 1839.

- Extracto de um manuscripto que se conserva na Bibliotheca de S. M. o Imperador e que tem por título - Descripção Geographica da America Portuguesa, sem autor, 1839.

- Thesouro descoberto no Maximo Rio Amazonas, João Daniel, 1840, 1841.

- Memoria sobre as nações gentias que habitam o continente do Maranhão, Francisco de Paulo Ribeiro, 1841.

- Qual era a condição do sexo feminino entre os indígenas do Brazil? José Joaquim Machado de Oliveira, 1842.

- Observações ou notas illustrativas dos primeiros três capítulos da parte segunda do Thesouro descoberto no Rio Amazonas, Antonio Ladisláo Monteiro Baena, 1843.

- Sobre os usos, costumes e linguagem dos Appiacás, e descobrimento de novas minas na Província do Mato Grosso, José da Silva Guimarães, 1844.

- Parecer sobre o aldeamento dos índios uaicurus e guanás com a descrição dos seus usos, religião, estabilidade e costumes, Ricardo Franco de Almeida Serra, 1845.

- Artigo extraído do "Panorama", sem indicação de autor, 1845.

- Noticia raciocinada sobre as aldeãs de índios da província de S. Paulo, desde seu começo até a actualidade, José Joaquim Macedo de Oliveira, 1846.

- Informação dos casamentos dos índios do Brasil, José de Anchieta, 1846,.

- Relatorio da exposição dos rios Mucury e Todos os Santos, Vitor Reinault, 1846. 
- As villas de Caravellas, Viçosa, Porto Alegre, de Mucury, e aos rios Mucury e Peruhipe, Hermenegildo Barboza d'Almeida, 1846.

- Os orizes conquistados ou noticia da conversão dos indômitos Orizes Procazes povos habitantes e guerreiros do Sertão do Brasil, novamente reduzidos á Santa Fé Catholica e á obediencia da Coroa Portugueza, Joseph Freire de Monterroyo Mascarenhas, 1846.

- Viagem e visita do sertão em o Bispado do Gram-Pará em 1762 e 1763, João de S. José, 1847.

- O Caramuru perante a historia, Francisco de Adolfo Varnhagen, 1848.

- Memoria a respeito dos rios Raures, Branco da Conceição, de S. Joaquim, Itomas e Maxupo, Francisco José de Lacerda e Almeida, 1849.

- Dissertação histórica, etnográfica e política, Ignácio Accioli de Cerqueira e Silva, 1849.

- Carta etnographica indígena, línguas, emigrações e archeologia, padrões de mármore dos primeiros descobridores, Francisco Adolfo Varnhagen, 1849.

- Memoria sobre o descobrimento, governo, população e cousas mais notaveis da capitania de Goyaz, Luiz Antonio da Silva e Souza, 1849.

- Relação Geographica Histórica do Rio Branco da America Portugueza, Francisco Xavier Ribeiro de Sampaio, 1850.

- Continuação do parecer sobre os índios uaicurus, guanás, Ricardo Franco de Almeida Serra, 1850.

- Memoria histórica e documentada das aldeãs de Índios da Província do Rio de Janeiro, Joaquim Norberto de Souza Silva, 1854.

- Amazonas, Antonio Gonçalves Dias, 1855.

- Noticia sobre os selvagens de Mucury, Theophilo Benedicto Ottoni, 1858. 
- Os cayapós. Sua origem, descobrimento, accometimentos pelos mamelucos; represália, meios empregados com violência e com arma em punho para subtrail-os as mattas, esses meios substituídos pelos de brandura; seus benefícios resultados; aldeamento; conclusão, Machado Vieira, 1861.

- Diário da viagem feita pelos sertões de Guarapuava ao Rio Paraná, Camilo Leite da Silva, 1865.

- Noticia da situação de Matto Grosso e Cuyabá, estado de umas e outras minas e novos descobrimentos de ouro e diamante, José Gonçalves da Fonseca, 1866.

- Memoria e considerações sobre a população do Brasil, Henrique Jorge Rebello, 1867.

- Noticia etnonologica sobre um povo que já habitou a Costa do Brasil, bem como o seu interior, antes do dilúvio universal, Carlos Rath, 1871.

- Archeologia. Relíquias de uma grande tribu extinta, Antonio Manoel Gonçalves Tocantins, 1876.

- Estudos sobre a tribu Mundurucu, Antonio Manoel Gonçalves Tocantins, 1877.

- Povoação do Brazil relativamente á origem e influencia dos primeiros povoadores portuguezes nos costumes nacionaes, José Silvestre Rebello, 1882.

- Diário da viagem philosophica pela capitania de São José do Rio Negro, Alexandre Rodrigues Ferreira, 1887.

- As populações indígenas e mestiças da Amazônia, José Veríssimo, 1887.

Temos também alguns textos que são permeados por esses três domínios. Esses textos buscam falar sobre a estrutura da língua (aspectos fonéticos, ortográficos, sintáticos), a significação, a história das palavras, além de descreverem ou os indígenas ou o território nacional. São estes: 
- Memoria sobre o descobrimento da Colônia de Guarapuava, Francisco das Chagas Lima, 1842.

- Brasil e Oceania, Antonio Gonçalves Dias, 1867.

- Um manuscripto Guarany, Antonio de Joaquim de Macedo Soares, 1880.

- Ensaio de Antropologia. Religião e raças selvagens, José Vieira Couto Magalhães, 1873.

- Questões propostas sobre alguns vocábulos da língua geral braziliana, Francisco Freire Allemão, 1882.

No domínio dos instrumentos linguísticos, temos:

\section{Domínio dos Instrumentos Linguísticos}

- Notícia sobre os Botocudos acompanhada de um vocabulário de seu idioma e algumas observações, M. Jomard, 1847.

- Vocabulário da Língua Bugre, não há a indicação de autoria, 1852.

- Collecção de vocábulos e frazes usados na província de S. Pedro do Rio Grande do Sul, Antonio Álvares Pereira Coruja, 1852.

- Vocabulário da Língua Geral usada hoje em dia no Alto Amazonas, Antonio Gonçalves Dias, 1854.

- Vocabulário dos Índios Cayuás, oferecido pelo Barão de Antonina, 1856.

- O Dicionário Topográfico da Província do Espírito Santo, Braz da Costa Rubim, 1862.

- Vocabulário da Língua Guaná ou Chané, Alfredo d'Escragnolle Taunay, 1875.

- A Grammar and vocabulary of the tupi language, John Luccock, 1880, 1881. 
- Vocábulos indígenas e outros introduzidos no uso vulgar, Braz da Costa Rubim, 1882.

- Dicionário Histórico e Geográfico das Campanhas do Estado Oriental do Uruguay e Paraguay, João Vicente Leite de Castro, 1887.

- Os índios Caingangs e seu dialecto, Alfredo d'Escragnolle Taunay, 1888.

- Vocabulário Puri, Alfredo de Noronha Torrezão, 1889.

Como podemos notar pelos títulos, diversos são os tipos de textos que falam sobre as línguas indígenas. Podemos perceber que há diferentes tipos textuais sendo produzidos/documentados pela RIHGB. Contudo, é necessário ressaltar que neste trabalho as diferentes tipologias textuais não fazem parte de nossas preocupações centrais. Como Orlandi (2002, p. 86), estamos considerando que o que caracteriza o discurso, "antes de tudo, não é seu tipo, é seu modo de funcionamento". Em nosso trabalho, os diferentes textos funcionam por meio de um discurso linguístico/científico que buscam caracterizar a produção de um saber linguístico nos domínios: (i) da letra, (ii) da palavra, (iii) do comentário linguístico e (iv) dos instrumentos linguísticos.

Nesses domínios, as línguas contempladas são as línguas indígenas. O olhar se voltava para o índio e seu falar. Nesses trabalhos, podemos notar a disciplinarização de estudos que se voltam para o saber linguístico. Esses estudos são entremeados pelos estudos geográficos, antropológicos, etnográficos e históricos. Disciplinariza-se um saber linguístico enciclopédico em que diversos domínios contribuem para a constituição de um dizer sobre as línguas do Brasil e de suas fronteiras. É o início de uma linguística brasileira sendo divulgada na RIHGB durante o século XIX.

A partir da análise das Revistas e sua divisão nos domínios, uma questão se fez presente: como o IHGB, com sua prática de documentação, divulgação, sistematizou a produção concernente ao século XIX da RIHGB? Para respondermos a essa questão, analisamos a RIHGB n. 400. 


\section{A RIHGB N. 400: UMA PRÁTICA DE LEITURA, INTERPRETAÇÃO E DIVULGAÇÃO}

A Revista do IHGB n. 400 constitui um índice em que a divisão em temas dos textos publicados nas RIHGB anteriores a essa publicação pode ser vista. Nossa análise desse material justifica-se, uma vez que, pelo modo como se categoriza em temas, podemos perceber como sentidos vão surgindo e sendo divulgados, enquanto outros vão sendo apagados, esquecidos, silenciados. Nosso objetivo é analisar o modo como, no século XX, se organiza a produção concernente ao século XIX da RIHGB, buscando analisar como, ao se dividir em temas, atribuem-se sentidos às coisas, aos sujeitos, aos espaços, aos acontecimentos brasileiros.

A Revista do IHGB n. 400, publicada em 1998 em comemoração aos 160 anos do IHGB, busca dar conta de uma periodicidade de 159 anos da Revista do IHGB. Trata-se de um índice dividido em assunto, título e autor. Temos também um texto (Apresentação) do Presidente do IHGB (Arno Wehling) e um texto (Introdução) assinado pela direção da Revista.

Consideramos a Revista n. 400 um texto documentador que sistematiza a documentação de obras (textos) sobre diversos temas produzidos ou coletados pela RIHGB. De acordo com Nunes (2008, p. 83), convém distinguir os textos a serem documentados (obras) dos textos documentadores (descrições, comentários, resumos, indexações, bibliografias, periodizações etc.):

Uma obra passa a ser um "documento" na medida em que ela é historicizada, ou seja, na medida em que ela se torna objeto de um saber documental. O texto documental nomeia, data, seleciona objetos e traça percursos. Sua tipologia é variada e caracteriza-se pelo caráter metalingüístico. Por vezes ele se apresenta inserido em um texto teórico, outras vezes apresenta-se como texto de arquivo, com o objetivo reconhecido de documentação (NUNES, 2008, p. 83). 
A Revista n. 400 se apresenta com o objetivo de documentação: "fazia falta, entretanto, um índice que cobrisse o conjunto da produção da Revista, atualizado até nossa época e dentro dos moldes técnicos". Assim, com o objetivo de refletir sobre a prática de documentação efetuada pela Revista do IHGB, analisaremos como os textos documentais, especificamente relacionados ao saber linguístico, foram reunidos e divulgados nesse texto documentador que constitui a Revista do IHGB n. 400. Antes, porém, analisaremos os textos introdutórios que fazem parte desse número.

O texto de Apresentação, de Arno Wehling, é curto (uma página) e discorre, de maneira geral, sobre a importância de um trabalho de indexação como o realizado pelo IHGB no ano de 1998. Em nossa análise das revistas, vimos que, durante o século XIX, temos a publicação de alguns índices nas Revistas do IHGB, todavia são índices menores que dão conta de uma pequena periodicidade da Revista.

Arno Wehling aponta em seu texto o significado de uma prática de indexação. Esta se justifica em virtude do "aumento da informação":

Com o avassalador aumento da informação disponível em todos os campos do conhecimento, os procedimentos de indexação têm, cada vez mais, um papel relevante a desempenhar, constituindo-se em verdadeiros guias para temas, autores e questões estudadas. Da indexação bíblica, onde tudo começou, ao menos no mundo ocidental, às obras fundadoras de nossa cultura, este ininterrupto trabalho de classificar, ordenar e relacionar as informações é um dos pilares do conhecimento (IHGB - Apresentação).

No interior de um discurso das tecnologias da informação, Arno Wehling constitui seu dizer sobre a RIHGB n. 400. A Revista surge como um objeto em que estarão classificadas, ordenadas e relacionadas as "informações" de 159 anos da RIHGB. São, para Arno Wehling, as práticas de indexação um dos pilares do conhecimento, pois por meio de índices, funcionando como "guias", um pesquisador encontra temas, autores, questões que podem se tornar objetos de estudo. A imagem que o presidente do IHGB constitui para essa obra é a de um auxiliar às 
pesquisas, uma vez que um saber ali está organizado. O uso da palavra 'guia' abre para uma multiplicidade de sentidos: um guia indica caminhos, traça percursos, seleciona sentidos que devem ser divulgados e outros que devem ser silenciados.

Para Arno Wehling, os periódicos científicos, como a Revista do IHGB, representam um desafio à indexação. Isso porque:

Pela sua própria finalidade e natureza, possuem material diversificado. Resultados de pesquisas, completos ou como notas prévias, estudos, ensaios, relatórios, cartas, resenhas bibliográficas e documentos constituem um acervo multifacetado que foi crescendo. Quando a publicação, como esta Revista do Instituto Histórico e Geográfico Brasileiro, alcança o número 400, cada qual com algumas centenas de páginas, estamos diante de uma monumenta que corre o risco de se tornar muito arduamente decifrável, com a informação diluída em volumes, partes e seções e nem sempre intitulada pelos próprios autores à cartesiana, com idéias claras e distintas (IHGB - Apresentação).

Nesse trecho, temos uma imagem do índice como um facilitador de pesquisas diante da monumenta que é a RIHGB. Por meio da "diluição" do conhecimento se "decifra" o que foi produzido no IHGB. Temos a imagem do saber como algo possível de ser segmentado, fragmentado em "partes", e é essa divisão (“diluição") que auxilia na clareza das ideias. Temos uma filiação a um discurso racionalista das ideias que busca concisão e clareza.

A RIHGB (desde o século XIX até hoje) é vista como um grande acervo, "repositório de investigações e de documentos". A Revista do IHGB se constitui como um lugar de memória, um lugar que arquiva a história e a geografia do Brasil. Assim, a Revista do IHGB n. 400 surge como mais um instrumento ("guia") que contribuirá para que seja preservado, "decifrado" e divulgado um saber sobre a nação brasileira.

A Introdução da Revista do IHGB n. 400 é assinada pela Direção da Revista. Não temos um sujeito específico apontado como autor do texto. É um locutor coletivo que formula a enunciação. Nessa Introdução, podemos notar como o passado e o presente passam a 
funcionar no discurso da Revista n. 400. As práticas do passado dão legitimidade às práticas do presente. A Introdução inicia-se salientando que:

É com indisfarçável júbilo que o IHGB coloca nas mãos de seus sócios e demais leitores a presente edição de sua tradicional Revista, ora atingindo o $n^{\circ} 400$. A publicação, vale lembrar, em antiguidade e constância - festejando 159 anos de fecunda existência e que jamais teve interrompida sua circulação - ocupa o primeiro lugar nas três Américas, e no Mundo cede esta honrosa posição apenas para outra Revista (IHGB - Introdução).

Nota-se aqui uma ampliação em relação ao público leitor da Revista. No século XIX, a circulação da Revista era restrita. Seus leitores eram somente os membros do IHGB (sócios) e as instituições nacionais e estrangeiras com as quais o IHGB mantinha contato. Já na RIHGB n. 400, ademais dos sócios do IHGB, essa revista também se direciona ao público em geral, caracterizando assim uma prática de divulgação científica. Nesse trecho inicial vemos, além disso, sendo ressaltado o lugar de notoriedade alcançado pela Revista do IHGB. Esse lugar foi conquistado em virtude da elevada qualidade dos trabalhos da instituição.

$\mathrm{Na}$ continuidade da Introdução, traça-se um percurso histórico sobre a Revista do IHGB. Salientam-se suas primeiras publicações, sua periodicidade, as tipografias em que a Revista era impressa. Esses fatos são explicitados objetivando explicar como se dá o funcionamento atual da Revista e seu índice, que é trazido à publicação. Vejamos:

$\mathrm{O} \mathrm{n}^{\circ}$ 400, que estamos trazendo a lume, não corresponde, matematicamente, ao número de anos que a publicação tem de idade, em se tratando de órgão trimensal. Explica-se: o $\mathrm{n}^{\circ} 1$, impresso pela Typographia da Ass. do Despertador, dirigida por J.M. da Rocha Cabral, sócio fundador do Instituto Histórico e Geográfico Brasileiro, instalado na Rua da Quitanda, $n^{\circ} 55$, no Rio de Janeiro, veio à luz em abril de 1839, e, fazendo as contas, deveríamos estar lançando o $n^{\circ} 590$. Essa diferença reside no fato de, nos primeiros anos, até 1862, ter saído apenas um volume por 
ano. Desse ano em diante, até 1942, foram publicados dois volumes anuais, tendo sido intercalado na numeração, em 1888, um terceiro volume, o de $\mathrm{n}^{\circ} 78$, de Suplemento. Somente a partir de 1943 , iniciou-se de fato com volume $\mathrm{n}^{\circ} 178$, a publicação trimensal (IHGB - Introdução).

Nesse trecho, ressalta-se como de fato ocorreu a circulação da Revista do IHGB. O projeto da Revista era uma publicação trimestral, todavia isso só passará efetivamente a acontecer no ano de 1943, mais de 100 anos depois da publicação do primeiro tomo da RIHGB. De certo modo, traz-se o real ao discurso, e o funcionamento imaginário do que deveria ser a Revista aparece no fio do discurso. Essa volta ao passado vem justificar algo que se passa no presente: a numeração da Revista $n^{\circ}$ 400 .

Após esses comentários relativos à periodicidade da Revista, indicam-se, em um percurso histórico, as tipografias que faziam a publicação da Revista até chegar à Imprensa Nacional - "órgão do governo” - responsável pela publicação da revista desde 1926. Aqui temos uma relação com o governo sendo estabelecida. Antes a publicação da Revista era realizada por tipografias particulares, até que, em 1922, por meio de um convênio, em virtude de um decreto assinado pelo Presidente da República, Epitácio Pessoa, passa-se à Imprensa Nacional. Mostra-se uma filiação do IHGB com o governo Republicano - este, de algum modo, auxiliando o IHGB na publicação da Revista. Contudo, não sem alguns momentos de conflito:

São percalços hoje vencidos e, com a introdução, há 4 anos ocorrida, do envio da matéria diretamente em disquetes de computador para as oficinas gráficas, não acreditamos possam acontecer novos atrasos, mormente quanto contamos com um perfeito entrosamento entre o Rio de Janeiro e Brasília. Referida modernização, conseqüência do inexorável progresso de técnica de comunicação e retenção da memória, não foi aceita de imediato por alguns, mas já se firmou, uma vez que proporciona absoluta fidelidade entregue pelos autores. E há mais: desde 1996 a Imprensa Nacional, vindo ao encontro de anseios dos autores das matérias estampadas, fornece-lhes, graciosamente, 30 
separatas dos artigos, devidamente encapadas (IHGB Introdução).

Nesse excerto, há uma filiação aos discursos da modernidade, das tecnologias da informação, da teoria da comunicação. Aponta-se também uma certa resistência no início desse processo, mas depois uma aceitação em virtude dos "benefícios" que a modernização traz para a "comunicação" e para a "retenção da memória". É uma memória até certo ponto metálica, uma vez que as relações entre os autores e as "oficinas gráficas" são mediadas pelo computador. São as novas tecnologias fazendo parte do IHGB.

Finalizando a Introdução, a Direção da Revista agradece a seus colaboradores e aponta que:

Decorridos tantos anos desde o número inicial e publicadas muitas centenas de títulos, julgamos oportuno o momento, na verdade inadiável, para inserir nesta longa série de contribuições culturais um número especial, de índices, abrangendo desde a primeira publicação, de abril de 1839, até a de n³99 (abril-junho de 1998). Para a sua consecução pusemo-nos em atividade desde cedo, sempre com integral apoio da Diretoria do IHGB, que contratou até pequena equipe para que, auxiliando o corpo de bibliotecárias da instituição, pudéssemos entregar em tempo hábil esta contribuição aos nossos confrades e leitores em geral, e assim concorrer, a nosso modo, para abrilhantar as comemorações programadas para a data magna, 21 de outubro do ano corrente. É, por conseguinte, também uma homenagem que a atual administração da Revista presta a todos aqueles que com seu quinhão de trabalho coadjuvaram para a sua grandeza, desde os 27 fundadores da Instituição até aqueles, de todos os níveis, que nesta casa labutam na data presente. Esperamos que o magno esforço despendido na elaboração do presente volume se projete igualmente sobre as gerações vindouras e, assim pensando, repetimos Carpent tua poma nepotes - Teus netos colherão os frutos (Virgílio, Éclogas, IX, 50) (IHGB - Introdução). 
Nesse discurso de exaltação, o passado, o presente e o futuro são colocados em cena. Rememoram-se os fundadores do IHGB - como um gesto cultural - e para homenageá-los, a Revista do IHGB n400. Esta, documentando e divulgando práticas passadas e surgindo hoje como um instrumento de pesquisa - essa pesquisa baseada nas teorias da comunicação e da informação. Curioso perceber essas filiações teóricas da RIHGB n. 400. Não se fala tanto em história, como no século XIX, mas sim na facilidade e na velocidade com que essas "informações" podem chegar aos pesquisadores consulentes.

Analisemos, então, a RIHGB n. 400.

Como já ressaltamos, a RIHGB n. 400 se divide em temas. Para a análise especificamente nos baseamos na parte do índice Assunto. Analisamos especificamente três temas dessa divisão: Dicionário, Lingua e Índios. Esses temas foram selecionados porque são eles que perpassam a produção sobre um saber linguístico divulgado na RIHGB no século XIX. Pretendemos notar: que textos são contemplados em tais tematizações? Que sentidos circulam? Que sentidos são apagados? Como um discurso, que se coloca como cultural, informacional, divulga um saber produzido no Brasil do século XIX?

No tema Dicionário e Lingua, temos contemplados os seguintes textos:

\section{Dicionário}

- Dicionário abreviado tupinambá-português: apêndice a Poranduba maranhense, 1891.

- Dicionário da língua geral do Brasil, 1891.

- Dicionário histórico e geográfico das campanhas do Estado Oriental do Uruguai e Paraguai, 1887.

\section{Língua}

- Vocabulário da língua bugre, 1852. 
- Explicação conveniente acerca do trabalho de Pablo Restivo sobre a língua guarani, 1895.

- A língua geral do Amazonas e o guarani, 1888.

- Um manuscrito guarani, 1880.

- Palavras guaranis, 1897.

- Partículas de la lengua guarani, 1895.

- Questões propostas sobre alguns vocábulos da língua geral brasiliana, 1882 .

- Coleção de vocábulos e frases usados na província de São Pedro do Rio Grande do Sul, 1852.

- Coleção de etimologias brasílicas, 1846.

- Memória sobre a necessidade do estudo e do ensino das línguas indígenas do Brasil, 1841.

- A grammar and vocabulary of the tupi language, 1880.

- Vocabulário da língua geral usada hoje no alto do Amazonas, 1854.

Nessa divisão, as línguas documentadas são: tupinambá, língua geral do Brasil, lingua geral do Amazonas, língua geral brasiliana, lingua brasílica, lingua tupi, lingua geral usada no alto do Amazonas, lingua guarani e lingua bugre. Ademais, temos uma obra em língua portuguesa (Coleção de vocábulos e frases usados na província de São Pedro do Rio Grande do SuD) e uma obra de especialidades (Dicionário Histórico e Geográfico das Campanhas do Estado Oriental do Uruguai e Paraguai). Há somente uma língua (bugre) que não pertence ao tronco Tupi-Guarani ${ }^{6}$, as demais fazem parte desse tronco. Essa divisão constitui o imaginário de que as línguas que têm estatuto de língua são as do tronco Tupi-Guarani, além de apagar o multilinguismo existente no Brasil. No texto Memória sobre a necessidade do estudo e do ensino das linguas indígenas do Brasil, podemos notar que não há a indicação de quais línguas indígenas devem ser ensinadas e estudadas. No entanto, essa divisão proposta pela RIHGB n. 400 permite-nos pensar que

\footnotetext{
${ }^{6}$ Pertencente ao Tronco Macro-Jê.
} 
somente as línguas do tronco Tupi-Guarani são objeto de um estudo. Cria-se o imaginário de que as "línguas indígenas do Brasil" são somente as nomeadas nessa parte do índice. De acordo com Barros (1990), "no mundo acadêmico do século XIX, o Instituto Histórico e Geográfico Brasileiro foi a principal instituição responsável pela produção e difusão dessa visão normativa do tupi”. Embora haja uma predominância da descrição de línguas pertencentes ao tronco tupi-guarani, na documentação do século XIX realizada pela RIHGB, como buscamos mostrar por meio de uma divisão em domínios da produção da RIHGB, outras famílias linguísticas indígenas (tronco tupi-guarani, macro-jê, família aruak) também são analisadas e descritas. Ademais, temos obras monolíngues e de especialidades que não são contempladas nas diversas tematizações do índice.

O modo como o índice se constitui por temas (aqui, especificamente, língua e dicionário) encobre a diversidade linguística do Brasil. O índice leva a pensar que no espaço de "estudo e ensino" das línguas indígenas do Brasil só teríamos as línguas gerais (tupi-guarani) e que somente essas línguas foram gramatizadas e constituíam objeto de interesse do IHGB. Na RIHGB n. 400, a língua tupi-guarani dá unidade no espaço multilíngue que é o Brasil; é essa imagem de homogeneidade, que apaga a diversidade, que se historiciza nessa tematização do índice e que se sustentará no tema Índios.

A tematização Índios se constitui da seguinte forma: há a indicação do grupo indígena mais a indicação do tema do texto referente aos indígenas. Essas tematizações vão indicando os sentidos do índice. Vejamos:

\section{Índios Aimoré - Condições Sociais}

- Qual era condição do sexo feminino entre os indígenas do Brasil?, 1842. 


\section{Índios Apiacá - Mato Grosso}

- Memória sobre os usos, costumes e linguagem dos Apiacás e descobrimento de novas minas na província de Mato Grosso, 1844.

\section{Índios Bororo - Glossários, Vocabulários, etc.}

- Vocabulário da língua dos Bororos-Coroados do Estado de Mato Grosso, 1918.

Os temas contemplados nessa parte do índice são: condições sociais; glossários, vocabulários, etc.; usos e costumes; direitos civis; lendas; relações com o governo; religião e mitologia; línguas - estudo e ensino; dicionários, línguas. A tematização dicionários e línguas aparece duas vezes: uma sem a indicação do grupo indígena e outra com a indicação do grupo. Com a indicação só parece essa estrutura temática uma única vez, fazendo referência aos índios Tupinambá:

\section{Índios Tupinambá - Dicionários}

- Dicionário abreviado tupinambá-português: apêndice a Poranduba Maranhense, 1891.

- Dicionário da língua geral do Brasil, 1891.

\section{Índios Tupinambá - Línguas}

- Dicionário abreviado tupinambá-português: apêndice a Poranduba Maranhense, 1891.

- Dicionário da língua geral do Brasil, 1891. 
Mais uma vez tem-se a imagem do tronco Tupi (língua geral, tupinambá) como o tronco legitimado para ser tratado como "língua", "dicionário". Os trabalhos relativos aos outros grupos indígenas não fazem parte dessa tematização, mas sim da "glossário e vocabulários". A língua indígena legitimada pela RIHGB é a pertencente ao tronco TupiGuarani, as outras línguas aparecem secundariamente e fazem referência a um saber sobre o índio e não em relação à sua língua.

Os "Vocabulários e Glossários" contemplados nesse índice são:

Índios Bororo - Glossários, Vocabulários, etc.

- Vocabulário da língua dos Bororos-Coroados do Estado de Mato Grosso, 1918.

Índios Caiapó - Vocabulários, Glossários, etc.

- Vocabulários indígenas, 1892.

Índios Caingangue - Glossários, Vocabulários, etc.

- Vocabulário do dialeto caingang, 1888.

Índios Carajá - Vocabulários, Glossários, etc.

Vocábulos indígenas, 1892.

Índios da América do Sul - Brasil - Glossários, Vocabulários, etc.

- Notas sobre a história pátria, 1876, 1877, 1878, 1879.

- Vocábulos indígenas e outros introduzidos no uso vulgar, 1882. 


\section{Índios da América do Sul - Rio de Janeiro (RJ) - Glossários, Vocabulários, etc.}

- Os topônimos indígenas do Rio de Janeiro quinhentista, 1967.

Índios Guaná - Glossários, Vocabulários, etc.

- Vocabulário da língua guaná ou xane, 1875.

Índios Munduruku - Glossários, Vocabulários, etc.

- Estudos sobre a tribo Mundurucu, 1977.

Índios Puri - Glossários, Vocabulários, etc.

- Vocabulário Puri, 1889.

Índios Tukuna - Glossários, Vocabulários, etc.

- Gramática, dicionário, verbos e frases e vocabulário prático da língua dos índios Tucunas, 1944.

Nessa tematização, temos alguns glossários e vocabulários contemplados. Estes não estão presentes na tematização Língua e Dicionário. Qual seria o critério de tematização? Essas outras línguas não teriam o estatuto de língua? Apaga-se, como já ressaltamos, as línguas pertencentes ao tronco Macro-Jê. A divisão em temas é feita pela nomeação do grupo indígena (índios bororo, caingangue, guaná, mundurucu, puri) e não por sua língua. Esse gesto de documentação apaga as outras línguas e o imaginário de unidade e de representatividade da língua tupi é explicitado. Ademais, podemos perceber uma flutuação 
nas nomeações: ora o vocabulário é de língua, ora de dialeto, ora é somente pelo nome do grupo indígena, ora aparece sob a nomeação "vocábulos indígenas", não especificando a que grupo pertence. Não há uma estabilidade nessas nomeações. Além disso, podemos perceber, comparando com a nossa divisão em domínios, que diversos textos e instrumentos linguísticos não aparecem na RIHGB n.400.

As línguas do tronco Tupi-Guarani aparecem nas três tematizações: Dicionários, Línguas e Índios. Essa repetição reforça o imaginário de que as línguas indígenas do Brasil pertencem ao tronco Tupi-Guarani. Além disso, por essa tematização, podemos dizer que há uma separação do sujeito-leitor. O índice divide a sociedade, os sujeitos. $\mathrm{Na}$ tematização Língua e Dicionário, teríamos textos direcionados a linguistas, a estudiosos das ciências da linguagem. Já na tematização Índios, ao sujeito antropólogo - daí as outras tematizações trazidas ao tema Índios. Ao sujeito antropólogo interessam as condições sociais, os usos, os costumes, os direitos civis, as lendas, a religião, a mitologia dos indígenas. Para produzir um saber sobre o indígena é necessário saber sobre a vida desses, além da língua que falam.

Finalizando, na análise desses temas pudemos perceber a nãocompletude ao categorizar-se as falhas, os equívocos que um gesto de documentação produz no real e no imaginário da linguagem. Apagam-se alguns sentidos para tornar transparentes outros. A Revista n. 400, como um texto documental e de divulgação, estabiliza sentidos e vai construindo um discurso racional, classificatório, em que podemos ver como as línguas do tronco Tupi-Guarani, em uma relação de força, se sobrepõem às línguas de outros troncos indígenas, tais como as do tronco Macro-Jê, criando um imaginário de unidade, de homogeneidade. Embora até se apresente a diversidade das línguas do Brasil, esta é homogeneizada na tematização, gerando assim um controle do multilinguismo existente no Brasil desde o início da colonização. Esse controle ocorreu pelo extermínio dos indígenas, por sua catequização, por sua civilização, pelo controle dos sentidos, pela imposição de uma unidade à diversidade. É esse discurso que a RIHGB n. 400 divulga em seu índice ao desconsiderar certos textos na tematização. O discursofonte é reformulado e um discurso segundo surge. É esse discurso segundo que se mostra como um discurso de documentação da produção das RIHGB. 


\section{CONSIDERAÇÕES FINAIS}

Nosso objetivo neste trabalho foi explicitar o modo como analisamos o IHGB e sua Revista. Refletimos sobre a divulgação de um saber linguístico nas RIHGB. Como mostramos, os trabalhos publicados nas RIHGB sobre um saber linguístico brasileiro são baseados nos domínios: (i) do comentário linguístico - em que se nomeiam seres e coisas, fala-se sobre a forma da língua, sobre sua história - (ii) da letra em que se realiza um estudo sobre os sons das línguas e sua representação ortográfica - (iii) da palavra - em que a unidade de análise é a palavra em sua história (uso) e em sua etimologia; (iv) dos instrumentos linguísticos - em que são documentados dicionários (bilíngues, monolíngues e de especialidades).

Analisando a Revista do IHGB n. 400, explicitamos como funciona a tematização em uma revista. A Revista n. 400, como um texto documental, estabiliza sentidos e vai construindo um discurso da história em que podemos ver como as línguas do tronco Tupi-Guarani, em uma relação de força, se sobrepõem às línguas de outros troncos indígenas, tais como as do tronco Macro-Jê, criando um imaginário de unidade, de homogeneidade. Embora até se apresente a diversidade das línguas do Brasil, esta é homogeneizada na tematização, gerando assim um controle do multilinguismo existente no Brasil desde o início da colonização.

Por fim, é no Instituto Histórico e Geográfico Brasileiro que uma história, uma geografia, uma ciência relativa ao Brasil e suas formas são construídas e legitimadas; é na Revista do Instituto Histórico e Geográfico Brasileiro, tanto nas edições do século XIX como na de 1998, que esse dizer científico, articulado à história e à geografia, pode ser lido, contado e divulgado pelos próprios sujeitos que o constituem, ou seja, os brasileiros. É por meio do gesto de documentação que um discurso sobre o saber linguístico brasileiro é divulgado pela RIHGB. 


\section{REFERÊNCIAS}

AUTHIER-REVUZ, J. Palavras incertas: as não-coincidências do dizer. Campinas: Editora da Unicamp, 1998.

FARIA, M. A. de O. Os brasileiros no Instituto Histórico de Paris. Revista do IHGB, v. 266, p. 64-148, 1965.

GUILHAUMOU, J.; MALDIDIER, D. Efeitos do arquivo. A análise do discurso no lado da História. In: ORLANDI, E.P. (Org.). Gestos de leitura: da história no discurso. Campinas: Editora da Unicamp, 1993.

GUIMARÃES, M.L.S. Entre amadorismo e profissionalismo: as tensões da prática histórica no século XIX. Topoi, Rio de Janeiro, n. 5, p. 184-200, jul./dez. 2002. Disponível em:

$<$ http://www.revistatopoi.org/numeros_anteriores/topoi05/topoi5a7.pdf>. Acesso em: 23 nov. 2011.

Nação e civilização nos trópicos: o Instituto Histórico e Geográfico Brasileiro e o projeto de uma história nacional. Estudos Históricos, Rio de Janeiro, n. 1, p. 5-27, 1988.

GUIMARÃES, L.M.P. Debaixo da imediata proteção de sua majestade imperial: o Instituto Histórico e Geográfico Brasileiro (1838-1889). Revista do IHGB. Rio de Janeiro, v. 156, n. 388, jul./set. 1995.

; HOLTEN, B. O Instituto Histórico e Geográfico Brasileiro, a Real Sociedade dos Antiquários do Norte e o Dr. Peter Wilhelm Lund: a suposta presença escandinava na Terra de Santa Cruz e a ciência. In: INTERNATIONAL CONGRESS OF THE LATIN AMERICAN STUDIES ASSOCIATION. 20., 1997, Guadalajara. Anais... Guadalajara, 1997.

Disponível em: < http://lasa.international.pitt.edu/LASA97/guimholten.pdf>. Acesso em 23 nov. 2011.

NUNES, J.H. O discurso documental na história das idéias lingüísticas e o caso dos dicionários. Alfa, São Paulo, v. 52, n. 1, p. 81-100, 2008.

ORLANDI, E.P. Análise de Discurso. In: RODRIGUES-LAGAZZI, S.; ORLANDI, E.P. (Orgs.). Introdução às ciências da linguagem: discurso e textualidade. Campinas: Pontes, 2006. p. 11-31.

2002.

Análise de discurso: princípios e procedimentos. Campinas: Pontes, 
PÊCHEUX, M. Discurso: estrutura ou acontecimento. Campinas: Pontes, 1990.

. Ler o arquivo hoje. In: ORLANDI, E.P. (Org.). Gestos de leitura: da história no discurso. Campinas: Editora da Unicamp, 1993.

REVISTA DO IHGB. Rio de Janeiro, Ano 159, n. 400, p. 643-1563, jul./set., 1998.

SCHWARCZ, L. M. O espetáculo das raças: cientistas, institutos, instituições e questão racial no Brasil: 1870-1930. São Paulo: Companhia das Letras, 1993.

Guardiões de nossa história oficial. São Paulo: Idesp, 1989.

ZOPPI-FONTANA, M. Cidadãos modernos. Campinas: Editora da Unicamp, 1997.

Recebido em 02/10/11. Aprovado em 15/12/11.

Title: The documentation and divulgation of the linguistic knowledge in Revista do IHGB

Authors: Dantielli Assumpşão Garcia; José Horta Nunes

Abstract: In this paper, from the theoretical perspective of Discourse Analysis in conjunction with the History of Linguistic Ideas, we will examine the practice of documentation and divulgation of the linguistic knowledge accomplished by Revista do Instituto Histórico e Geográfico Brasileiro. To this end, we firstly analyze the Revistas do IHGB from the 19th century (1839-1889), showing how the linguistic knowledge is constituted in the discourse of IHGB and subsequently the Revista do IHGB n. 400 (1998), index which organizes and divulges all RIHGB production from 1839 until 1998. As theoretical notions we mobilized concepts such as archive, linguistic documentation, and scientific divulgation. Our aim is to show how the documentation and divulgation stabilize some meanings and obliterate some others in the Brazilian linguistic knowledge.

Keywords: Linguistic documentation. Scientific divulgation. Revista do IHGB.

Titulo: La documentación y la divulgación Del saber linguistico em la Revista Del IHGB

Autores: Dantielli Assumpşão Garcia; José Horta Nunes

Resumen: En este trabajo, de la perspectiva teórica del Análisis de Discurso en articulación con la Historia de las Ideas Linguísticas, discurriremos sobre la práctica de documentación y divulgación del saber linguístico realizada por la Revista del Instituto Histórico y Geográfico Brasileño. Para eso, analizaremos inicialmente las Revistas del IHGB del siglo XIX (1839-1889), mostrando como el saber linguístico se constituye en el discurso del IHGB y, enseguida, la Revista del IHGB n 400 (1998), indice que organiza y divulga toda la producción de la RIHGB desde 1839 hasta 1998. Movilizamos como nociones teóricas: archivo, documentación linguistica y divulgación cientifica. Pretendemos, con este trabajo, mostrar como la documentación y la divulgación estabilizan algunos sentidos y borran otros para el saber linguistico brasileño.

Palabras-clave: Documentación linguística. Divulgación cientifica. Revista del IHGB.

GARCIA; NUNES - A documentação e a divulgação... 
